\title{
Alternating hemiplegia of childhood: First South African case report and verapamil as a possible treatment option
}

\author{
L S van Hillegondsberg, $\mathrm{MB} \mathrm{ChB}$; I A Michaelis, $\mathrm{MD}, \mathrm{PhD}$ \\ Department of Paediatrics, Frere Hospital, East London, South Africa
}

Corresponding author: L S van Hillegondsberg (ludovhill@gmail.com)

In this case report we describe a child with alternating hemiplegia of childhood, a rare neurodevelopmental disorder, and the effectiveness of an unconventional drug, verapamil, in treating this condition.

S Afr Med J 2019;109(3):152-153. DOI:10.7196/SAMJ.2019.v109i3.13757

Alternating hemiplegia of childhood (AHC) is a very rare neurodevelopmental disorder, with an estimated incidence of 1 in $1000000 .{ }^{[1]}$ The presentation can be highy variable, but the seven accepted diagnostic criteria are as follows: $(i)$ onset before 18 months of age; (ii) repeated episodes of hemiplegia involving the right or left side of the body, at least in some episodes; (iii) episodes of quadriplegia, starting directly or as generalisation of a hemiplegic episode; (iv) other paroxysmal disturbances, including tonic/dystonic attacks, nystagmus, strabismus, dyspnoea, and other autonomic phenomena occurring during hemiplegic attacks or in isolation; (v) immediate disappearance of all symptoms on going to sleep, with recurrence 10 - 20 minutes after awakening; $(v i)$ evidence of developmental delay, learning disability, neurological abnormalities, choreoathetosis, dystonia or ataxia; and (vii) not attributable to another disorder. ${ }^{[1-3]}$ The diagnosis of AHC was previously based solely on clinical manifestations, but in 2012 mutations in the ATP1A3 gene encoding the sodium-potassium ATPase $\alpha 3$ subunit were identified as the primary genetic cause of the disease. ${ }^{[4]}$ In recent years it has also become apparent that this clinical entity is probably part of a wider spectrum of disorders seen with these mutations. The other well-described conditions included in this spectrum are rapidonset dystonia parkinsonism and CAPOS syndrome (cerebellar ataxia, areflexia, pes cavus, optic atrophy and sensorineural hearing loss). These conditions are therefore sometimes collectively referred to as ATP1A3-related disorders. ${ }^{[4-6]}$

Management of AHC is challenging and no specific treatment exists. ${ }^{[1-3]}$ The aim of treatment is to reduce the frequency and severity of the episodes, and to manage them when they occur. Avoiding triggers can be helpful if any have been identified, but generally patients need long-term drug therapy. ${ }^{[1]}$ A range of therapies have shown some promise, but the currently accepted first-line therapy is flunarizine, a calcium-channel blocker. ${ }^{[1-3,7-10]}$ This is largely based on a case series by Mikati et al. ${ }^{[11]}$ where treatment with flunarizine resulted in a $78 \%$ reduction in duration, severity and frequency of hemiplegic episodes. Subsequent studies have shown similarly positive results, if not as impressive. ${ }^{[12]}$ Unfortunately flunarizine is not readily available in South Africa (SA). An alternative that has shown some promise is topiramate, especially in the setting of concomitant epilepsy or migraine. ${ }^{[7]}$ In SA topiramate is only available as a patient-motivated drug in the public healthcare sector. Furthermore, a thorough literature search revealed no previous publications on AHC in SA. Managing this unique disorder is therefore challenging in our context. The following case report aims to provide some illumination.

\section{Case report}

A 5-year-old boy was referred to the paediatric neurology clinic at Frere Hospital, East London, with poorly controlled epilepsy and developmental delay. The seizure morphology was described by the mother, who reported that the child would have unprovoked, sudden-onset paralysis of one side of the body. At times this would start by only affecting one arm, but as the episode continued the paralysis would spread to the ipsilateral leg. The boy would remain fully alert, and would be able to talk, eat and - with less severe episodes - walk. These episodes would last a variable amount of time lasting from a few hours to up to 5 days, and would then resolve completely with no residual effects. No urinary or faecal incontinence occurred. The frequency of the episodes was unpredictable, ranging from several times a week to only once a month. Occasionally both sides of the body would be involved (quadriplegia) and dystonic hand movements were reported. Notably, the mother revealed that the paralysis would resolve if the child went to sleep during these episodes and would return 15 - 20 minutes after waking.

The medical history revealed that the child was diagnosed with epilepsy at the age of 7 months (when these episodes began) and was treated with an array of antiepileptic drugs. By the age of 5, high-dose phenobarbitone $(7 \mathrm{mg} / \mathrm{kg} / \mathrm{d})$, high-dose sodium valproate $(30 \mathrm{mg} / \mathrm{kg} / \mathrm{d})$, carbamazepine and clonazepam had been tried, with no improvement. In over 4 years, the longest asymptomatic period was less than 2 months and the drugs had no effect on the duration or severity of episodes once they occurred. The only family history was that the child's mother was known to have myasthenia gravis. He had started preschool, but could not cope and had been removed owing to what the school had labelled as uncontrolled epilepsy.

On examination, he appeared as a friendly young boy with global developmental delay. He had no dysmorphic features. His weight, height and head circumference were between 0 and $-1 z$-scores. He spoke in short sentences and was able to perform simple tasks. He 
was noted to be hyperactive and was not able to sit down to copy shapes. On further examination he had strabismus, a normal gait, normal power, normal muscular tone and normal reflexes. He was unable to hop or stand on one leg and was unable to follow the instructions for the diadochokinesis or finger-nose tests. All other systems were unremarkable. Previous work-up for the presumed diagnosis of epilepsy included basic blood investigations, lumbar puncture, an electroencephalogram and a computed tomography scan of the brain, which were all normal.

Based on the boy's history, the clinical findings and the results of the special investigations, he met all of the seven accepted criteria and was diagnosed with AHC. Unfortunately genetic testing for the ATP1A3 mutation is not available in SA. All the anticonvulsants were stopped, and as flunarizine is not available in SA and topiramate could only be obtained through a patient-named motivation, it was decided to start him on verapamil in the interim. Verapamil was largely chosen because of its availability and similar mechanism of action to flunarizine, and it had shown some positive results in previous cases. ${ }^{[9]}$

One month later, after the verapamil dose had been slowly increased to $6.6 \mathrm{mg} / \mathrm{kg} / \mathrm{d}$ in three divided doses, the boy was tolerating the treatment well with no adverse effects. Over the next 6 months there was a marked reduction in the frequency, severity and duration of the hemiplegic episodes. Episodes only occurred about once a month, the extent of the paralysis with each episode was less severe, and symptoms would always resolve in less than 24 hours. Owing to the improved control of his episodes he was able to enrol successfully in a special-needs school. His continued progress is currently being closely monitored.

\section{Discussion}

This is the first case report of AHC in SA. An interesting aspect is the diagnosis of AHC in a black African child. Previous publications on AHC do not always disclose the ethnicity of the participants, but the vast majority of patients were from European and American centres, which may suggest that the diagnosis, and the ATP1A3 mutation, are very rare in the black population. The other element of note is the perceived efficacy of verapamil as a treatment option for AHC. The marked reduction in episode frequency, severity and duration reported by the caregiver, a 6 -month period free of major debilitating episodes and the subsequent enrolment in a special-needs school suggest that verapamil could be a viable alternative in treating AHC in the SA setting.

Informed consent to publication of this case report was obtained from the guardian of the patient.

Declaration. None.

Acknowledgements. None.

Author contributions. Both authors contributed equally to this case report. Funding. None.

Conflicts of interest. None.

1. Neville BG, Ninan M. The treatment and management of alternating hemiplegia of childhood. Dev Med Child Neurol 2007;49(10):777-803. https://doi.org/10.1111/j.1469-8749.2007.00777

2. Kansagra S, Mikati MA, Vigevano F. Alternating hemiplegia of childhood. Handb Clin Neurol 2013;112(3):821-826. https://doi.org/10.1016/B978-0-444-52910-7.00001-53

3. Dangond F. Alternating hemiplegia of childhood. In: Dangond F, ed. NORD Guide to Rare Disorders. Philadelphia: Lippincott Williams \& Wilkins, 2003:512-513.

4. Heinzen EL, Swoboda KJ, Hitomi Y, et al. De novo mutations in ATPIA3 cause alternating hemiplegia of childhood. Nat Genet 2012;44(9):1030-1034. https://doi.org/10.1038/ng.2358

5. Panagiotakaki E, de Grandis E, Stagnaro M, et al. Clinical profile of patients with ATPIA3 mutations in alternating hemiplegia of childhood - a study of 155 patients. Orphanet J Rare Dis 2015;10(1):123. https://doi.org/10.1186/s13023-015-0335-5

6. Carecchio M, Zorzi G, Ragona F, Zibordi F, Nardocci N. ATP1A3-related disorders: An update. Eur J Paediatr Neurol 2017;21(5): 257-263. https://doi.org/10.1016/j.ejpn.2017.12.009

7. Jiang WJ, Chi ZF, Ma L, et al. Topiramate: A new agent for patients with alternating hemiplegia of Jiang WJ, Chi ZF, Ma L, et al. Topiramate: A new agent for patients with alternating
childhood. Neuropediatrics 2006;37(04):229-233. https://doi.org/10.1055/s-2006-924721

8. Roubergue A, Philibert B, Gautier A, et al. Excellent response to a ketogenic diet in a patient with alternating hemiplegia of childhood. JIMD Rep 2014;15:7-12. https://doi.org/10.1007/8904_2013_292 9. Haffejee S, Santosh PJ. Treatment of alternating hemiplegia of childhood with aripiprazole. Dev Med Child Neurol 2009;51(1):74-77. https://doi.org/10.1111/j.1469-8749.2008.03192

10. Ju J, Hirose S, Shi XY, Ishii A, Hu LY, Zou LP. Treatment with oral ATP decreases alternating hemiplegia of childhood with de novo ATP1A3 mutation. Orphanet J Rare Dis 2016;11:55. https://doi.org/10.1186/ s13023-016-0438-7

11. Mikati MA, Kramer U, Zupanc ML, Shanahan RJ. Alternating hemiplegia of childhood: Clinical manifestations and long-term outcome. Pediatr Neurol 2000;23(2):134-141. https://doi.org/10.1016/ S0887-8994(00)00157-0

12. Pisciotta L, Gherzi M, Stagnaro M, et al.; IB AHC Consortium. Alternating hemiplegia of childhood: Pharmacological treatment of 30 Italian patients. Brain Dev 2017;39(6):521-528. https://doi. org/10.1016/j.braindev.2017.02.001

Accepted 11 December 2018. 